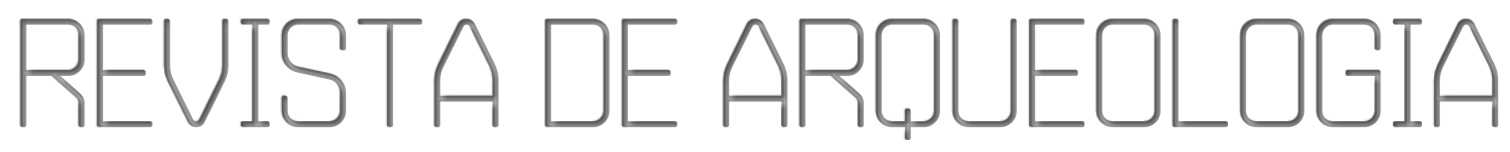

Volume 34 No.1 Janeiro-Abril 2021

\title{
SOBRE ARQUEOLOGIAS DA ESCRAVIDÃO E DA LIBERDADE
}

\section{Diogo Menezes Costa ${ }^{1}$}

O que é, hoje, o normal? Quando olhamos para um passado agora distante, vemos o reflexo de um futuro que ainda acontece no nosso cotidiano. É assim que nos sentimos ao acompanhar uma obra de referência como o livro organizado por Luis Cláudio Pereira Symanski e Flávio dos Santos Gomes, intitulado Arqueologias da Escravidão e Liberdade: Senzalas, Cultura Material e Pós-Emancipação na Fazenda do Colégio, Campos dos Goytacazes, Séculos XVIII a XX; editado pela recente Brazil Publishing, no ano de 2019. O livro é um estudo muito bem organizado sobre os resultados de várias pesquisas arqueológicas e históricas sobre um mesmo objeto de estudo, a fazenda do Colégio dos Jesuítas. Esse sítio foi o principal empreendimento escravagista no norte canavieiro fluminense que manteve em cativeiro cerca de duas mil pessoas até o último quartel do século XVIII.

Com um árduo trabalho que vem sendo desenvolvido desde 2009, o projeto de pesquisa surgiu pela união de duas pesquisas anteriores sobre o tema. As atividades arqueológicas de campo ocorreram no sítio durante o período de 2012 a 2016, demonstrando a eficácia das pesquisas prolongadas na arqueologia, as quais propiciam um entendimento de longa duração sobre o sítio. Sendo uma obra editada, cada capítulo trata de um tema, incluindo o passado histórico do local, as pesquisas arqueológicas contemporâneas, os estudos laboratoriais sobre os vestígios em louça industrial, a cerâmica artesanal, os restos bioarqueológicos, os pequenos objetos e a coleta das memórias atuais.

Composto por sete capítulos, o produto que nos chega as mãos é uma construção coletiva, e não poderia ser menos. Pois, assim como a própria arqueologia, que também produz de forma coletiva os seus conhecimentos sobre os passados. Culturas, sejam antigas ou atuais, são acúmulos de inúmeros patrimônios de e para todas e todos nós.

No primeiro capítulo Planícies Goitacazes, séculos XVIII e XIX: da escravidão africana atlântica ao campesinato no imediato pós-abolição, por Flávio dos Santos Gomes, temos uma aprofundada revisão histórica dessas longas planícies dos Goitacazes, onde se alojaram mais de 50\% dos engenhos do Rio de Janeiro no período colonial e concentrou mais de $40 \%$ de toda a população escravizada no período. O capítulo de Flávio Gomes é um exemplar estudo da materialidade documental de grupos que já não existem mais, mas que com seus descendentes ainda perduram não só o sangue, mas também o material e o imaterial.

Com um minucioso trabalho de colher em censos, o autor resgata desde a ancestralidade africana até os arranjos matrimoniais, bem como o legado geracional de uma população que foi sistematicamente escravizada e crioulizada, desde o século XVIII ao XIX na fazenda do Colégio. O investigador segue passando o olhar crítico na peneira dos documentos oficiais, como inquéritos policiais e atas da câmara, nos quais histórias

\footnotetext{
${ }^{1}$ Professor nos programas de pós-graduação em Antropologia e Ciências do Patrimônio Cultural na Universidade Federal do Pará. E-mail: dmcosta@ufpa.br. ORCID: https://orcid.org/0000-0003-4220-8232.
} 
não contadas diretamente por seus protagonistas, ainda relatam a resistência calada, mas firme de quilombos volantes, fugas e migrações na região. Por fim, o pesquisador chega até a escavação profunda das comunidades camponeses negras do pós-abolição, que apresentam a realidade, dos processos de trabalho e assentamento reestruturados, e que agora levam em conta novos interesses das elites e diferentes visões de liberdade de excativas e ex-cativos.

O capítulo dois de Luís Claudio Pereira Symanski, intitulado As pesquisas arqueológicas no Colégio dos Jesuítas, é um projeto à parte, pois o autor descreve minunciosamente todo seu labor prático e intelectual empregado no plano. O produto apresentado é de três campanhas seguidas e totalmente distintas, pois se ocuparam de estudar partes diferentes de uma mesma fazenda: as senzalas e as lixeiras, que geram vestígios arqueológicos de diversos períodos da materialidade humana.

Em 2012 o objetivo era investigar dois espaços concomitantemente com uma única escavação, uma possível estrutura de combustão dentro da senzala e provavelmente um depósito de refugo fora da senzala. Enquanto, a segunda escavação da mesma campanha de 2012 ocorreu também na área de descarte do solar. Posteriormente a segunda etapa de campanha em 2014 estudou outra senzala, agora na área oposta a sudoeste da fazenda, e a terceira campanha em 2016 pesquisou a porção nordeste em mais uma senzala, sendo que então, juntas, essas senzalas e a casa grande formavam o pátio. $\mathrm{O}$ resultado desse esforço foi a concepção de uma coleção substanciosa sobre o passado escravo e liberto do Brasil colonial e pós, fragmentos de vidas que foram devidamente pesquisados nas páginas seguintes deste livro.

No capítulo terceiro, também de Luís Cláudio Symanski, sobre Cerâmicas, linhas de cor e a negociação do espaço social no Colégio dos Jesuítas, somos agraciados com um diálogo sobre a condição material das louças e suas interpretações. O trabalho técnico do autor não é nenhuma sombra, sobre as possibilidades interpretativas que o estudo da materialidade humana propicia. Materialidade humanamente produzida que estava presente no jogo de relações pessoais que se estabeleciam intra e intergrupos, dos sobrados às senzalas do Colégio dos Jesuítas, revelando até a endogamia das comunidades escravizadas em uma economia de subsistência no Brasil do século XVIII.

No entanto perguntas suscitam: Como as pessoas escravizadas tiveram acesso a artigos em louça europeia? Seria doação, compra ou outra ação? Através da habilidade nata de que o autor dispõe para a aplicação na prática de uma teoria sobre os seus dados brutos, a escala econômica de Miller é exemplarmente usada, espacialmente localizada e simbolicamente interpretada, e o estudo sobre a materialidade humana da fazenda do Colégio dos Goitacazes portanto comprova, que a distinção social é um fenômeno antigo de prestígio. Contudo, nas senzalas dos Goytacazes, as relações são todas horizontais com os vivos, e só verticais para com os mortos.

Posteriormente, o quarto capítulo é escrito por Maurício Hepp, Paula de Aguiar Silva Azevedo e Victor Gomes Monteiro, com o título de Práticas e usos da cerâmica artesanal na senzala do Colégio dos Jesuitas, e apresenta o resultado das pesquisas sobre a variabilidade dos tipos cerâmicos e as suas relações com as práticas alimentares, tidas como forma de resistência das cativas e dos cativos.

A cerâmica neobrasileira-cabloca-colonial-local/regional estudada tem tantos nomes quanto significações, porém simboliza uma única coisa, a materialidade êmica de várias senzalas. Isso porque, através do tamanho dos potes, é possível estimar o número de usuários e assim saber que o consumo dos alimentos nas senzalas ocorria na forma de pequenos grupos. As cerâmicas revelam desde a organização do trabalho escravo na fazenda até a organização dos arranjos familiares e a perduração de uma herança africana por mais de 200 anos no local. O trabalho desenvolvido pelos autores é bem 
fundamentado, claro na exposição e tem muito a contribuir nas interpretações sobre a forma e função das vasilhas cerâmicas em contexto de escravidão.

O capítulo cinco chamado de Vestígios faunísticos e práticas relacionadas à alimentação na senzala do Colégio dos Jesuitas (RJ), de Geraldo Pereira de Morais Junior, é uma reflexão sobre os hábitos de aquisição e consumo de alimentos, através de biorresquícios recuperados no sítio. De forma metódica, o capítulo apresenta todo o processo de investigação do material orgânico recuperado, assim como interpretações sobre os seus contextos deposicionais, quantitativos e qualitativos. Esse estudo minucioso dos ossos permite saber qual o tipo de alimentação era a preferida, ou estava disponível, em cada setor das senzalas. O autor propõe-se então a perceber quais foram as estratégias de caça ou furto de animais silvestres e domésticos ao longo do tempo. Tais informações, em conjunto com outros estudos materiais do sítio, chegam assim a uma conclusão bastante crível em um sistema de opressão constante como o escravista: de que as iniquidades do aparelho eram sustentadas permanentemente até dentro das senzalas, provavelmente patrocinadas por atores de fora, que conduziam um acesso à alimentação de melhor qualidade apenas para certos grupos de escravas e escravos.

Em seguida, o capítulo seis do livro é uma surpresa à parte, escrito por Isabela Cristina Suguimatsu, versa sobre Para além de algemas e grilhões: os objetos de vestuário e ornamentação dos escravos. Em uma interpretação pioneira das "pequenas coisas esquecidas" nas senzalas brasileiras, a autora busca mais do que arqueografar achados, mas sim observar identidades emergentes dos artefatos pessoais recuperados nos contextos da escravidão. Constituídos em um mundo de regras sociais e econômicas, pequenos itens como botões, contas, braceletes, anéis, argolas, moedas e itens religiosos transmitem e armazenam informações entre entes. Partindo desse pressuposto, Suguimatsu olha atentamente para o cotidiano das escravas e escravos através desses pequenos itens e encontra gigantescos ritmos de vida nas senzalas do Colégio dos Jesuítas.

Entre esses ritmos estão as diferenças mínimas entre botões de madeira e louça, que podem marcar os espaços segregados nas senzalas e da casa grande. Ou quando uma sutil variação no tamanho nas contas de colar importadas de uma senzala comparada à outra pode também levar ao entendimento de distinções cronoespaciais entre certos grupos. Ou mais audaciosamente, quando a autora relaciona delicados braceletes e argolas, em cobre ou ouro, com a imensa herança de etnias africanas como Banto ou Mina. Portanto o que podemos apreender desse rico estudo é o imenso poder imbuído em certos diminutos itens, como as moedas perfuradas e adquirem valor também medicinal e religioso de outros tempos. Assim, diferentemente de imensos objetos da escravidão feitos para prender os corpos, outros singelos artefatos agora presos a esses mesmos corpos servem para libertar a mente e o espírito das cativas e cativos.

Por fim, o sétimo e último capítulo sobre Entre jongos e coisas esquecidas: por uma arqueologia da memória na Fazenda do Colégio, de autoria de Fernando Silva Myashita, corresponde ao belo encerramento de uma grande obra. Através de uma marca indelével nas suas páginas, as entrevistas com antigas(os) moradoras(es) do local descortina o que o autor delimita como uma pesquisa no campo da etnografia arqueológica. Em busca de práticas cotidianas e usos dos espaços, as sinuosidades da memória de hoje e da arqueologia do antes entrelaçam-se com as materialidades humanas presentes nos vestígios recuperados do agora e nas paisagens vividas de ontem. Myashita trabalha cuidadosamente com as memórias afetivas e legados familiares das pessoas que descendem das ex-cativas e dos ex-cativos na região, pois são esses registros "de cabeça" e de dentro das senzalas, como músicas, jogos, festas, espaços e hábitos, que, em contato 
com os vestígios arqueológicos expostos pela escavação, evocam lembranças para exviventes do local.

Desse modo, assim como a diversidade de ossos em uma quadrícula pode fascinar a nós pesquisadores sobre os hábitos alimentares de grupos em um passado, os mesmos ossos avistados por outros olhares, agora servem como gatilhos mnemônicos para lembranças de uma vivência de infância em quintais e pátios que hoje não são mais acessíveis. Em seu livro, Symanski e Gomes mostram não só contextos estáticos, mas relações dinâmicas de uma materialidade humana que ainda se faz presente a todo momento. A obra organizada por dois ilustres professores universitários com reconhecidas competências na área científica agrega ao seu núcleo excelentes pesquisadores, os quais, em conjunto, entregam um trabalho robusto e concatenado sobre as atuais pesquisas arqueológicas e históricas da escravidão e da liberdade no Brasil e no mundo.

Em última nota, enquanto escrevia este, texto teve início os eventos Black Lives Matter, que tomaram conta das ruas nas principais cidades norte-americanas e outras partes do mundo, derrubando estátuas e ressignificando monumentos pelo fim da discriminação racial. Isso porque neste momento que uma pandemia transforma o mundo em um novo normal, ainda me pergunto se a realidade de que trata esta obra está tão distante do nosso dia a dia e se não cabe a nós que estudamos tanto o ontem desconstruir também esses amanhãs, que já são tão antigos, ainda hoje.

Palavras-chave: Arqueologia; escravidão; liberdade.

Keywords: Archaeology; slavery; freedom.

Palabras clave: Arqueología; esclavitud; libertad.

\section{REFERÊNCIA BIBLIOGRÁFICA}

SYMANSKI, Luis Cláudio Pereira; GOMES, Flávio dos Santos. (ed.) Arqueologias da Escravidão e Liberdade: Senzalas, Cultura Material e Pós-Emancipação na Fazenda do Colégio, Campos dos Goytacazes, Séculos XVIII a XX. Curitiba: Brazil Publishing, 2019. DOI:10.31012/978-655016-272-6. 